
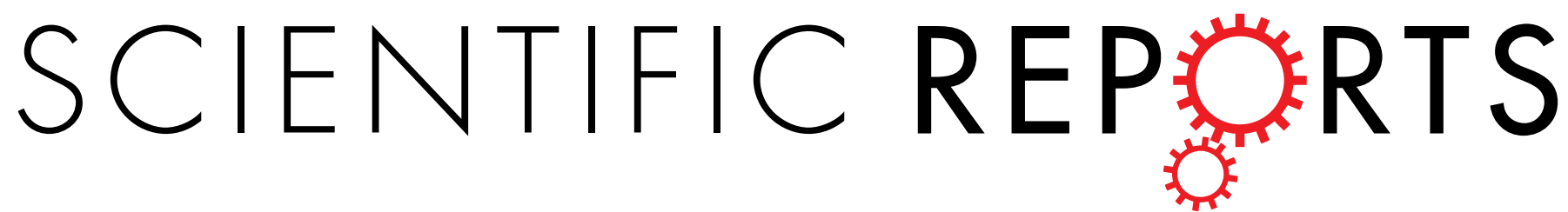

\title{
OPEN A Novel Resveratrol Based Tubulin Inhibitor Induces Mitotic Arrest and Activates Apoptosis in Cancer Cells
}

Received: 10 May 2016

Accepted: 14 September 2016

Published: 17 October 2016
Elizabeth Thomas ${ }^{1}$, Vidya Gopalakrishnan ${ }^{2}$, Mahesh Hegde ${ }^{1}$, Sujeet Kumar ${ }^{3}$, Subhas S. Karki ${ }^{3}$, Sathees C. Raghavan ${ }^{1}$ \& Bibha Choudhary ${ }^{2}$

Resveratrol is one of the most widely studied bioactive plant polyphenols which possesses anticancer properties. Previously we have reported synthesis, characterization and identification of a novel resveratrol analog, SS28. In the present study, we show that SS28 induced cytotoxicity in several cancer cell lines ex vivo with an $\mathrm{IC}_{50}$ value of 3-5 $\mu \mathrm{M}$. Mechanistic evaluation of effect of SS28 in non-small cell lung cancer cell line (A549) and T-cell leukemic cell line (CEM) showed that it inhibited Tubulin polymerization during cell division to cause cell cycle arrest at G2/M phase of the cell cycle at 12-18 $\mathrm{h}$ time period. Immunofluorescence studies confirmed the mitotic arrest upon treatment with SS28. Besides, we show that SS28 binds to Tubulin with a dissociation constant of $0.414 \pm 0.11 \mu \mathrm{M}$. Further, SS28 treatment resulted in loss of mitochondrial membrane potential, activation of Caspase 9 and Caspase 3, leading to PARP-1 cleavage and finally cell death via intrinsic pathway of apoptosis. Importantly, treatment with SS28 resulted in regression of tumor in mice. Hence, our study reveals the antiproliferative activity of SS28 by disrupting microtubule dynamics by binding to its cellular target Tubulin and its potential to be developed as an anticancer molecule.

Microtubules are cytoskeletal filaments in cells composed of two proteins $\alpha$ and $\beta$ Tubulin which are involved in many cellular functions such as formation of meiotic and mitotic spindle, cell motility, cell shape and transport of proteins and organelles ${ }^{1}$. Microtubules and their dynamics are targets of chemically diverse group of antimitotic compounds that are derived mostly from natural sources. Antimitotic agents inhibit cell proliferation by acting on the polymerization of spindle microtubules, which are essential for proper spindle function. Although the antimitotic drugs have been used clinically for treating diseases, the loss of efficacy over time due to development of resistance is considered as a major drawback ${ }^{2,3}$

The most successful microtubule targeting drugs includes Vinca alkaloids (Vincristine, Vinblastine, Vinorelbine, Vindesine and Vinflunine), paclitaxel and docetaxel. Among these, Vincristine and Vinblastine are Tubulin binding agents, bind to the Vinca domain and inhibit Tubulin assembly ${ }^{4,5}$. In contrast, paclitaxel and docetaxel bind to the taxane-binding site and stabilize microtubules without increasing microtubule polymerisation $^{6-8}$.

Resveratrol (trans-3, $4^{\prime}, 5$-trihydroxystilbene), a naturally occurring polyphenolic compound is highly enriched in the skin of red grapes, peanuts and various fruits. It has also been reported in the root of the plant, Polygonum cuspidatum, and an important constituent of Chinese and Japanese folk medicines ${ }^{9}$. Resveratrol has been extensively investigated as a cardioprotective, anti-inflammatory, and antiaging agent ${ }^{10-12}$. In addition, studies have shown that resveratrol has a strong chemopreventive effect against the development of cancers of skin, breast, prostate and lung ${ }^{10,13-16}$. Besides, effects of resveratrol in downregulation of angiogenesis-associated genes, activation of the apoptotic pathways and induction of cell cycle arrest have also been studied ${ }^{17-20}$.

Using resveratrol as the prototype, we have recently synthesised various analogs, evaluated their effect on cancer cell lines and identified (E)-1,2,3-trimethoxy-5-(4-methylstyryl)benzene (6h) (SS28) as the potent molecule ${ }^{21}$. In the present study we evaluate antiproliferative activity of SS28 in different cancer cells and show that SS28 treatment leads to G2/M arrest. In addition, we have determined binding affinity of SS28 to purified Tubulin. Further,

${ }^{1}$ Department of Biochemistry, Indian Institute of Science, Bangalore 560 012, India. ${ }^{2}$ Institute of Bioinformatics and Applied Biotechnology, Electronic City, Bangalore 560 100, India. ${ }^{3}$ Department of Pharmaceutical Chemistry, KLE University's College of Pharmacy, Bangalore 560 010, India. Correspondence and requests for materials should be addressed to S.C.R. (email: sathees@biochem.iisc.ernet.in) or B.C. (email: vibha@ibab.ac.in) 
A

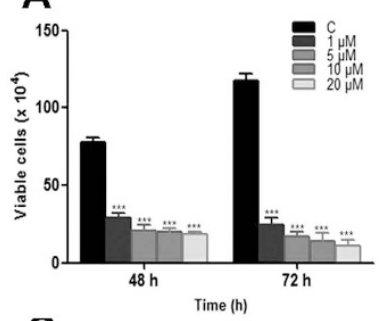

C

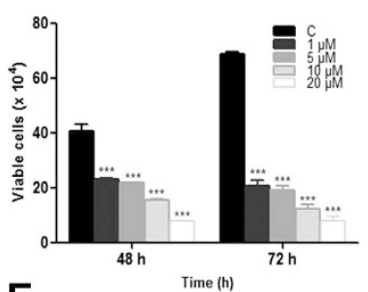

E
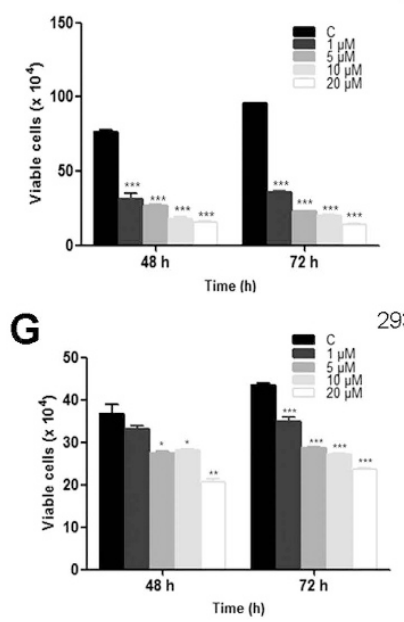

CEM

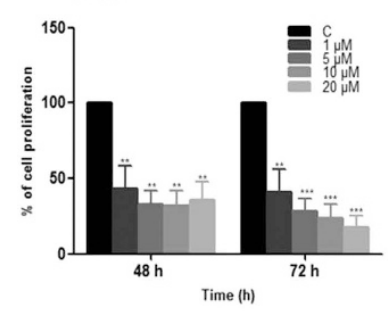

Molt4

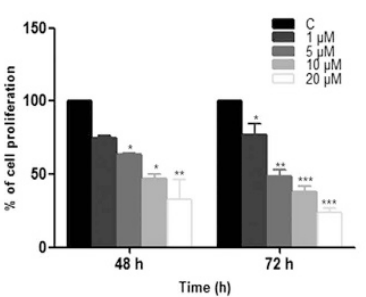

SUDHL8

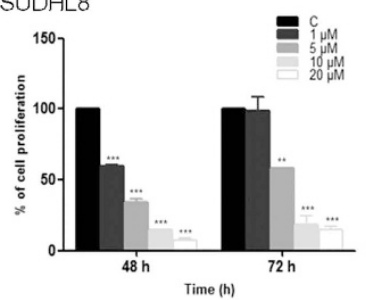

$293 \top$

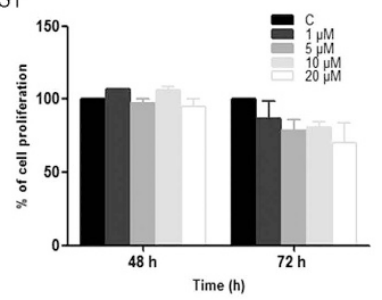

B

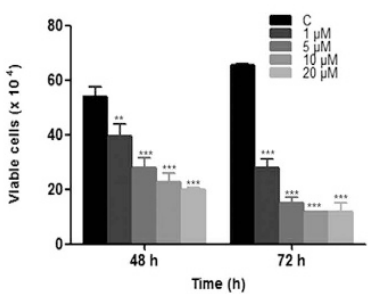

D
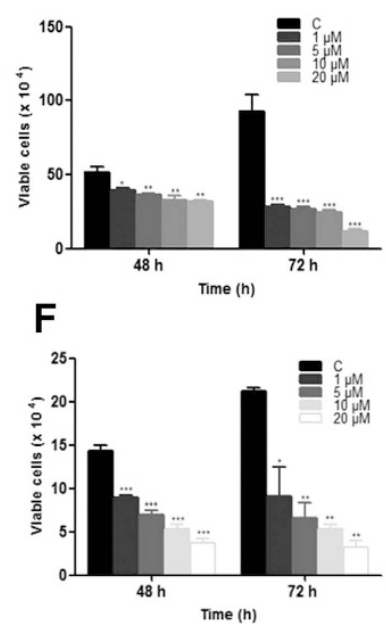

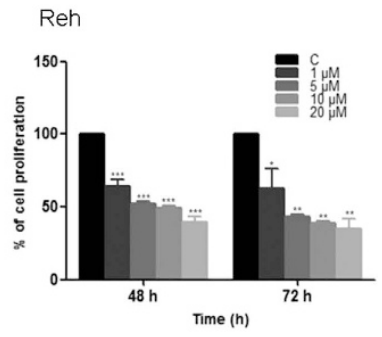

Nalm6

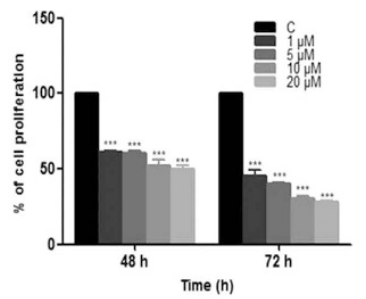

A549

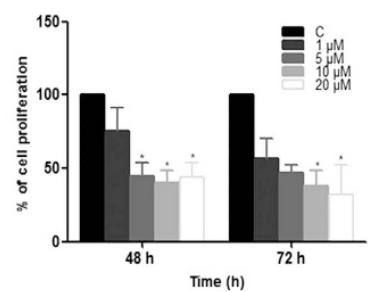

Figure 1. Effect of SS28 on cell viability in various cancer cell lines. Cells were cultured with increasing concentrations $(1,5,10$ and $20 \mu \mathrm{M})$ of SS28 for 48 and $72 \mathrm{~h}$. Trypan blue and MTT assays were performed to assess the cytoxicity induced by SS28. Cells treated with DMSO served as vehicle control. Different cancer cell lines, CEM (A), Reh (B), Molt4 (C), Nalm6 (D), SUDHL8 (E), A549 (F) 293T (G) were used for the study. Each experiment was repeated a minimum of three times. Error bars indicate the SEM and P value was calculated by comparing the mean of control group with mean of SS28 treated group, ${ }^{*} \mathrm{p}<0.05,{ }^{* *} \mathrm{p}<0.005,{ }^{* * *} \mathrm{p}<0.0001$.

we show that SS28 interferes with Tubulin polymerization leading to disruption of the formation of microtubule, which in turn leads to metaphase arrest. Eventually, SS28 treatment results in cell death by activating the intrinsic pathway of apoptosis.

\section{Results}

SS28 induces cytotoxicity in different cancer cell lines. Various leukemic cell lines (CEM, Reh, Molt4 and Nalm6), human lung carcinoma cells (A549), cervical cancer cell line (HeLa), Diffuse large B cell lymphoma cell line (SUDHL8) and human embryonic kidney epithelial cell line (HEK293T) were used for evaluating their sensitivity towards SS28 $(1,5,10$ and $20 \mu \mathrm{M})$. Cells treated with DMSO were used as vehicle control. Results of trypan blue assays showed that SS28 interfered with cell viability in a dose dependent manner (Fig. 1). Among the cell lines tested CEM and A549 exhibited maximum sensitivity to SS28 followed by SUDHL8, Molt4 and Reh, whereas Nalm6 showed moderate sensitivity after $48 \mathrm{~h}$ of the treatment (Fig. 1). $\mathrm{IC}_{50}$ values of SS28 in CEM and A549 cell line were 2.6 and $5.2 \mu \mathrm{M}$, respectively, whereas in SUDHL8, Molt4, Reh and Nalm6 were 2.7, 5.1, 7.9 and $21 \mu \mathrm{M}$, respectively after $48 \mathrm{~h}$ of treatment (Suppl. Table 1). Among the cancer cell lines studied, HeLa cells exhibited least sensitivity to SS28 $(32.4 \mu \mathrm{M})$ (Suppl. Table 1). Interestingly, SS28 induced only limited cytotoxicity on normal cell line HEK293T, compared to most of the cancer cells (Fig. 1). Besides, we also observed minimal effect on cell viability $(48 \mathrm{~h})$, when peripheral blood mononuclear cells (PBMC) were treated with SS28 with an IC $_{50}$ value $>35 \mu \mathrm{M}$ (Suppl. Table 1). However, when mouse embryonic fibroblast cells (MEF) were evaluated for their sensitivity to SS28, it exhibited significant cell death with an $\mathrm{IC}_{50}$ value $5 \mu \mathrm{M}$ (Suppl. Table 1 ). This is understandable as MEFs are known to proliferate efficiently and SS28 is most probably acting as a Tubulin inhibitor. Impact 


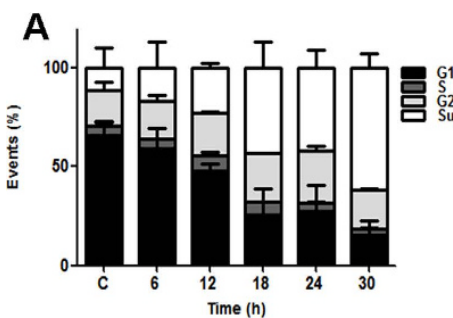

D
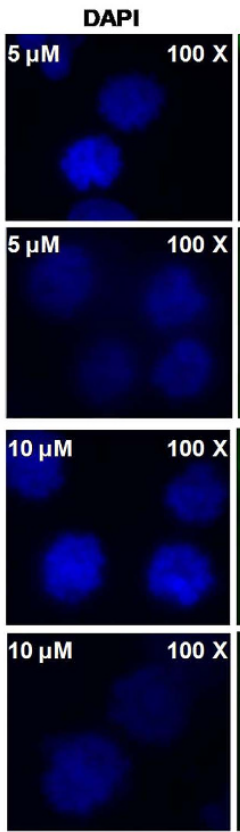

FITC
B
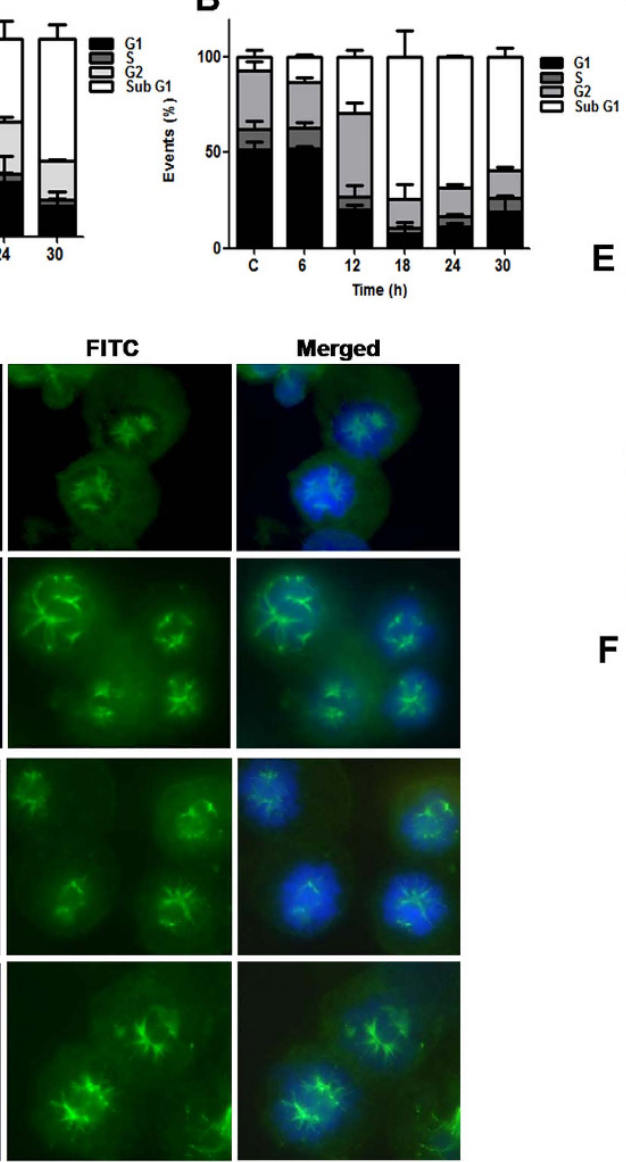

Merged
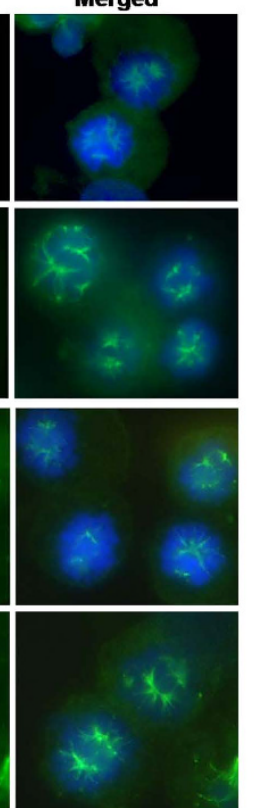

E

$\mathbf{F}$
C

\begin{tabular}{|l|l|l|}
\hline Category & $\begin{array}{c}\text { Total number } \\
\text { of cells }\end{array}$ & $\begin{array}{c}\text { Metaphase } \\
\text { arrest }\end{array}$ \\
\hline Control & 249 & 0 \\
\hline $5 \mu \mathrm{M}$ & 78 & 30 \\
\hline $10 \mu \mathrm{M}$ & 387 & 123
\end{tabular}
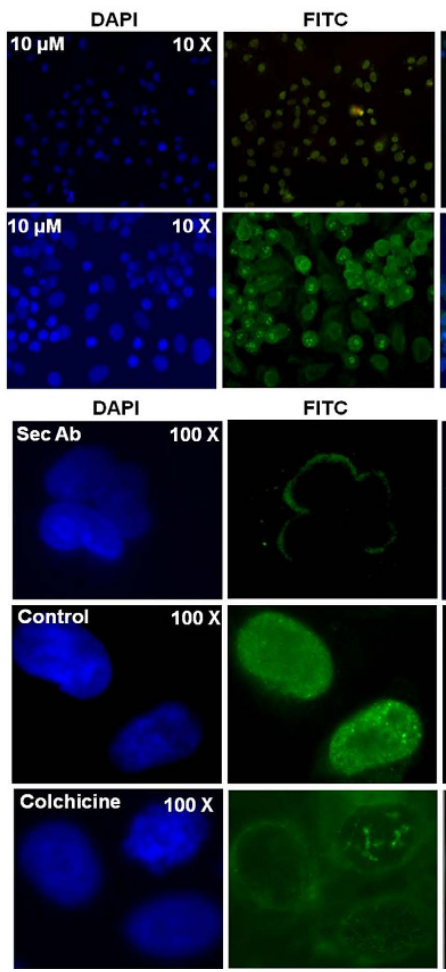

FITC

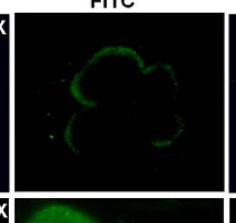

Merged

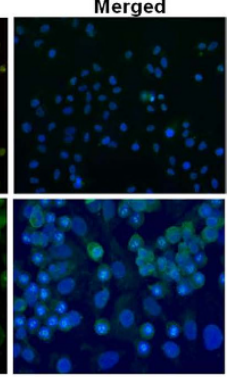

Merged

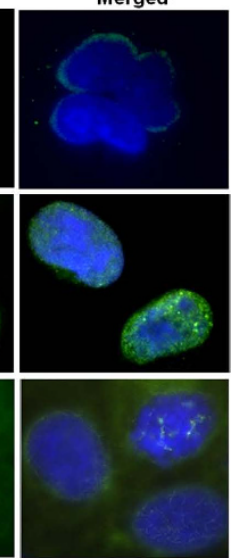

Figure 2. Effect of SS28 on cell cycle progression and spindle microtubule formation. $(A, B)$ Bar diagram summarising the \% of cells in each phase of cell cycle. A549 (A) and CEM (B) cells were treated with SS28, 5 and $2 \mu \mathrm{M}$, respectively for different time points $(6,12,18,24$ and $30 \mathrm{~h})$ and cell cycle phase distribution was analysed by flow cytometry. DMSO treated cells served as the vehicle control. (C-F) Effect of SS28 on spindle microtubule formation in A549 cells. A549 cells were cultured in presence of 5 and $10 \mu \mathrm{M}$ of SS28 for $24 \mathrm{~h}$. Cells were then fixed and labelled with a monoclonal $\alpha$-Tubulin (green) antibody conjugated to FITC and nuclei stained with DAPI (blue) as described in materials and methods. (C) Table representing the metaphase arrest in the control and treated cells after 5 and $10 \mu \mathrm{M}$ of SS28 treatment. Representative fluorescence images of control and treated cells in duplicates. (D) SS28 treated (5 and $10 \mu \mathrm{M})$ A549 cells showing bipolar spindles. (E) SS28 treated $(10 \mu \mathrm{M})$ A549 cells (10X view). (F) Single cell view of secondary antibody control, primary antibody treated control cells and Colchicine treated cell. Images shown are DAPI, FITC and merged, respectively.

of SS28 treatment on cell proliferation was also evaluated using MTT assay. Results showed that the proliferation of cells was affected maximally in the case of CEM, A549, Molt4 and SUDHL8 which was followed by Reh and Nalm6 after 48 h of treatment (Fig. 1). Taken together, our results suggest that SS28 affected cancer cell growth in all leukemic cells and lung cancer cells tested.

SS28 induces G2/M cell cycle arrest. To examine whether the growth inhibition observed is due to cell cycle arrest followed by apoptosis, A549 and CEM cells were treated with SS28 ( $5 \mu \mathrm{M}$ for A549 and $2 \mu \mathrm{M}$ for CEM) for various time points $(6,12,18,24$ and $30 \mathrm{~h})$ and cell cycle distribution was studied by flow cytometry. Results showed significant accumulation of cells at G2/M phase in a time-dependent manner ( 6 to $24 \mathrm{~h}$ ) and a subsequent increase in the sub-G1 population, indicative of apoptosis at $30 \mathrm{~h}$ in case of A549 (Fig. 2A; Suppl. Fig. 1A). Thus our result showed a prominent G2/M arrest following SS28 treatment in A549 cells.

Similarly, studies in CEM also showed a distinct G2/M arrest after $12 \mathrm{~h}$ of treatment, as compared to vehicle control (Fig. 2B; Suppl. Fig. 1B). However, further increase in incubation resulted in elevated levels of cell death accounting for observed increase in sub-G1 population. Therefore, our results suggest that SS28 treatment resulted in cell cycle arrest at G2/M phase leading to apoptosis upon further incubation.

Effect of SS28 on mitotic spindle organization. Since we observed G2/M phase arrest during cell cycle analysis, we checked whether SS28 affects organisation of spindle microtubule during mitotic progression of cells. To investigate this, lung cancer cell line, A549 was chosen as it showed significant G2/M arrest. A549 cells 
A

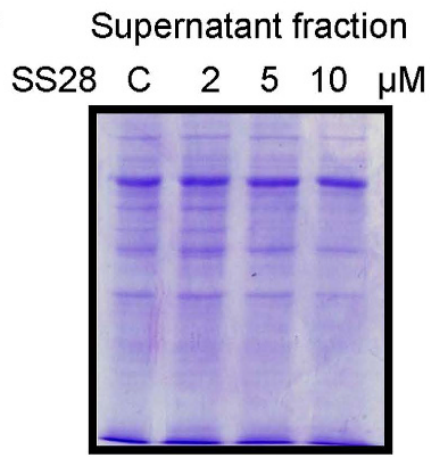

Pellet fraction
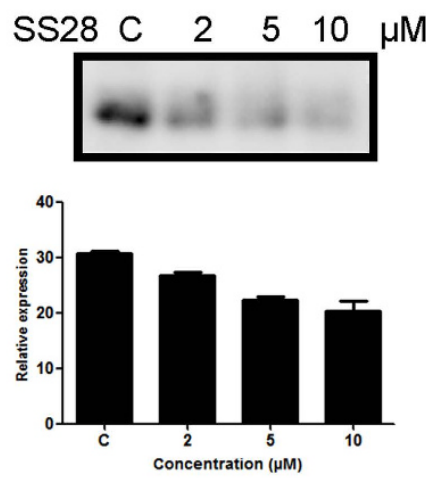

B<smiles>COc1cc(/C=C\c2ccc(C)cc2)cc(OC)c1OC</smiles>

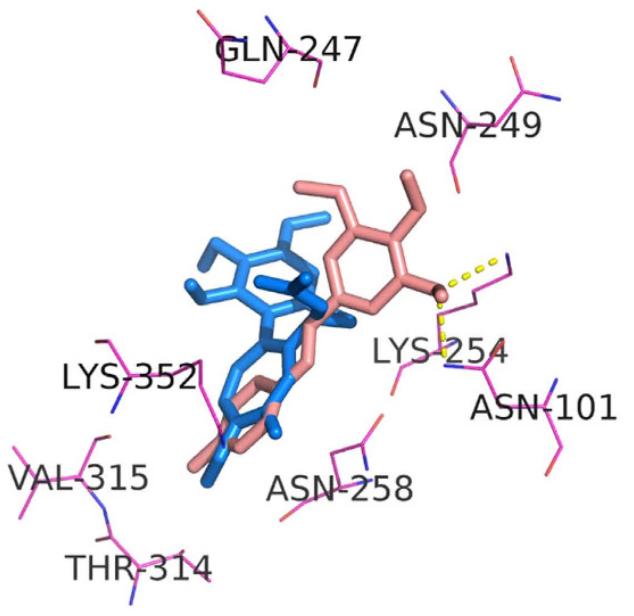

Figure 3. Docking studies showing SS28 interaction with Tubulin in colchicine binding site and the effect of SS28 on microtubule dynamics. (A) CEM cells were treated with SS28 $(2,5$ and $10 \mu \mathrm{M})$ and processed for the microtubule assembly assay. Supernatant fractions were resolved in $8 \%$ SDS-PAGE. The pellet fractions were immunoblotted using $\alpha$ - Tubulin antibody and quantified. (B) Structure of SS28. (C) Docked pose of SS28 with Tubulin. SS28 can interact with the colchicine binding pocket of Tubulin with the hydrogen bond interaction with Lys 254 and Asn 101. SS28 represented in red and colchicine in blue colour.

treated with SS28 $(0,5$ and $10 \mu \mathrm{M})$ for $24 \mathrm{~h}$ were processed for immunofluorescence microscopy studies (Fig. 2C). Results showed that $\sim 38 \%$ of the cells displayed abnormal spindle organisation upon treatment with $5 \mu \mathrm{M}$ of SS28 (Fig. 2C-F). Many cells had multipolar spindles, while others had aberrant bipolar spindles with misaligned chromosomes (Fig. 2D). Both multipolar spindles and abnormal bipolar spindles were also observed upon $10 \mu \mathrm{M}$ SS28 treatment (Fig. 2C-F). The observed abnormal spindle organisation could be due to the binding of SS28 to Tubulin, thereby preventing microtubule polymerisation. A large fraction of cells also showed chromosome condensation which is a characteristic feature of prometaphase stage of mitosis (Fig. 2E).

Further we used Colchicine treated A549 cells as a positive control for the study (Fig. 2F). Colchicine is known to destabilise microtubule assembly by binding to Tubulin ${ }^{19,22}$. Upon treatment with Colchicine, expected chromosome condensation and metaphase arrest was observed as compared to untreated cells (Fig. 2F). Thus, the compound SS28 significantly affected the microtubule formation leading to chromosome condensation, which was comparable to that of Colchicine.

SS28 affects the Tubulin polymerisation. Cell based Tubulin polymerisation assay was performed to check whether SS28 indeed affects the Tubulin polymerisation. Results showed that the pellet fraction containing the polymerised Tubulin decreased upon treatment with SS28 in a concentration dependent manner (Fig. 3A). In contrast, the supernatant fraction containing depolymerised microtubules remained equal in all the cases irrespective of the concentration (Fig. 3A). This suggests that SS28 inhibited the Tubulin polymerisation at a concentration of $2 \mu \mathrm{M}$ onwards due to its binding to Tubulin.

To gain insights about SS28 interaction with Tubulin, docking studies were carried out using Autodock4.2.program. Results showed that, methyl benzene group of SS28 can fit in the methoxytropone ring (ring C) of colchicine binding site of Tubulin (Fig. 3B,C). Besides the trimethoxy benzene group of SS28 is involved in the hydrogen bond interactions with Lys 254 and Asn 101 of Tubulin chain with a favourable binding energy of $-6.83 \mathrm{kcal} / \mathrm{mol}$ (Fig. 3C). Hence, docking studies revealed potential interaction of SS28 with Tubulin (Fig. 3C). Thus, our biochemical data in conjunction with docking studies suggest that SS28 can indeed target Tubulin within the cells. 

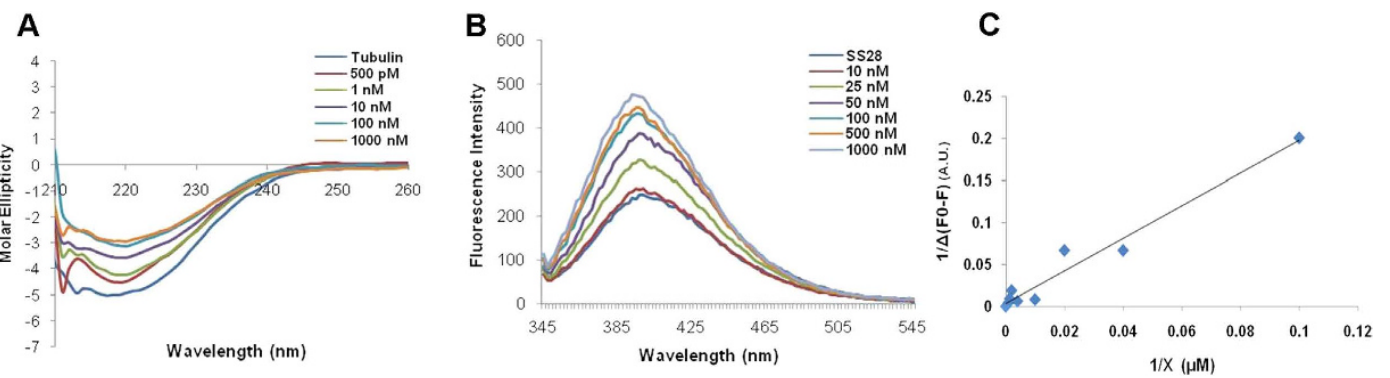

Figure 4. Evaluation of binding affinity of SS28 to Tubulin. (A) Circular dichroism studies were performed at $200-260 \mathrm{~nm}\left(4^{\circ} \mathrm{C}\right)$ on a JASCO J-810 spectropolarimeter. The spectra of Tubulin alone $(1 \mu \mathrm{M})$ in PEM buffer and in presence of increasing concentration of SS28 were recorded. Spectra of buffer containing corresponding concentrations of DMSO were subtracted from experimental data and presented. (B) Evaluation of change in fluorescence intensity when increasing concentration of Tubulin was added to SS28. Emission spectra of SS28 alone $(10 \mu \mathrm{M})$ or with increasing concentration of Tubulin $(10,25,50,100,500$ and $1000 \mathrm{nM})$ were recorded following incubation at $30^{\circ} \mathrm{C}$ for $30 \mathrm{~min}$. The fluorescence intensities were plotted against the wavelength. (C) The double reciprocal plot of SS28 binding to Tubulin. X axis indicates the concentration of Tubulin and $\mathrm{Y}$ axis represents the differences in the fluorescence intensity.

SS28 can bind to Tubulin. To test whether SS28 can directly bind to purified Tubulin, purified protein was incubated with increasing concentration of ligand $(500 \mathrm{pM}, 1,10,100,1000 \mathrm{nM})$ in PEM buffer and circular dichroism (CD) was performed. Results showed a shift in the spectrum when SS28 was added from as low as $500 \mathrm{pM}$ (Fig. 4A). Thus, addition of SS28 to Tubulin significantly increased the molar ellipticity suggesting alteration in the secondary structure of Tubulin. Further, fluorescence studies were conducted to evaluate the binding affinity of SS28 to Tubulin. SS28 exhibited fluorescence in aqueous solution, with an emission maximum at $399 \mathrm{~nm}$. The binding to purified Tubulin results in an induction of fluorescence in a concentration dependent manner (Fig. 4B). The change in fluorescence of SS28 was used to determine both association and dissociation. The double reciprocal plot of fluorescence data yielded a dissociation constant (Kd) of $0.414 \pm 0.11 \mu \mathrm{M}$ with a binding ratio 1:1 (Fig. 4C).

SS28 treatment did not result in ROS production. Intracellular ROS production was tested following treatment with SS28 $(2 \mu \mathrm{M})$ in CEM cells by flow cytometry after staining with $\mathrm{H}_{2}$ DCFDA (Suppl. Fig. 2A). Results did not show generation of ROS when tested for an incubation period as early as 5 min or at later time points (Suppl. Fig. 2). In contrast, the cells treated with $\mathrm{H}_{2} \mathrm{O}_{2}$ showed a distinct ROS production which served as positive control (Suppl. Fig. 2). Hence, our results suggest that SS28 treatment does not result in ROS production indicating that cell death is not caused by oxidative stress.

SS28 treatment affected the mitochondrial membrane potential. Mitochondrial membrane potential plays an important role in triggering apoptosis by regulating the membrane permeability ${ }^{23}$. Therefore, we checked the effect of SS28 treatment on mitochondrial membrane potential in CEM cells using JC- 1 staining followed by flow cytometry (Fig. 5A). The JC-1 dye, due to an inherent positive charge enters the mitochondrial matrix due to the negative charge established by the intact mitochondrial membrane potential. When intact mitochondrial membrane potential is absent due to a chemical treatment, JC- 1 accumulates in the cytoplasm in monomeric form characterized by green fluorescence. Upon treatment with SS28, a concentration dependant increase in the green fluoresced cells was observed in contrast to control cells which exhibited maximum red fluorescence (Fig. 5A,B). Hence our results suggest the loss of mitochondrial membrane potential upon treatment with SS28.

Treatment with SS28 resulted in apoptosis rather than necrosis. Previous studies suggested that microtubule-inhibiting agents cause G2/M phase arrest followed by apoptosis ${ }^{24,25}$. Hence, we used Annexin V-FITC/PI double-staining method to study apoptosis and necrosis following exposure to SS28 (5 and $10 \mu \mathrm{M}$ for $48 \mathrm{~h}$ ) in CEM cells. Results showed that SS28 induced apoptosis in a concentration dependent manner (Fig. 5C). At $5 \mu \mathrm{M}, 39.8 \%$ of cells were in late apoptosis while $28.2 \%$ in early apoptotic stage, whereas they were $46.9 \%$ and $32.9 \%$ respectively, when treated with $10 \mu \mathrm{M}$ of SS28 (Fig. 5C,D). However, we did not observe any cells undergoing necrosis (Fig. 5C).

SS28 treatment lead to alteration in the expression levels of cell cycle and apoptotic proteins. In order to study the mechanism by which SS28 induces cell cycle arrest and apoptosis, we studied the expression levels of some of the cell cycle and apoptotic markers. To accomplish this, CEM and A549 cells were treated with SS28 ( $5 \mu \mathrm{M}$ for 24,48 and $72 \mathrm{~h}$ ), cell lysates were prepared and used for western blotting studies. The level of Cyclin B1, a key regulator of cells entry into mitosis, was increased at $48 \mathrm{~h}$ time point in CEM cells followed by a decrease at $72 \mathrm{~h}$ (Fig. 6A,B). However, in case of A549 cell line, the Cyclin B1 level was maintained throughout the time period, but with a moderate decrease at $48 \mathrm{~h}$ (Fig. 6C,D). The expression level of Cdk6 was increased at $24 \mathrm{~h}$ followed by a decrease at 48 and $72 \mathrm{~h}$ in both the cell lines tested (Fig. 6).

To further investigate the underlying mechanism of action of SS28 on cancer cell lines, we examined the possible involvement of apoptotic proteins. Caspase 9, an indicator of intrinsic pathway of apoptosis, showed an 
A
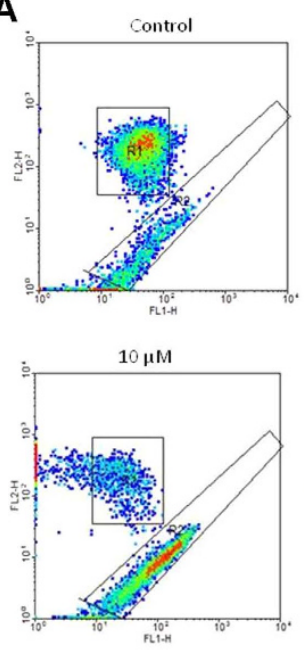

C

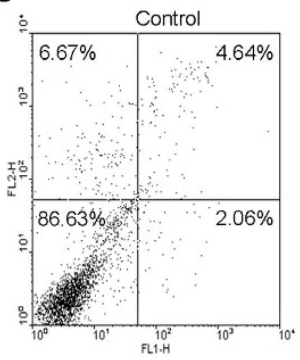

$1 \mu \mathrm{M}$

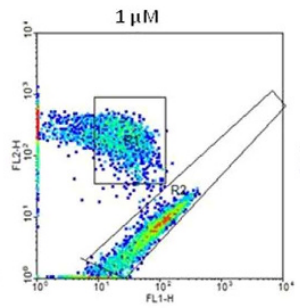

$20 \mu \mathrm{M}$
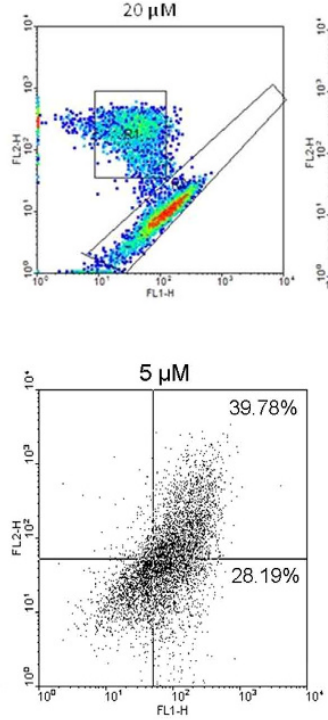

$5 \mu \mathrm{M}$

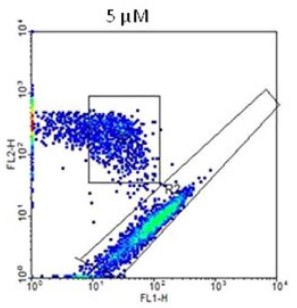

2,4, DNF
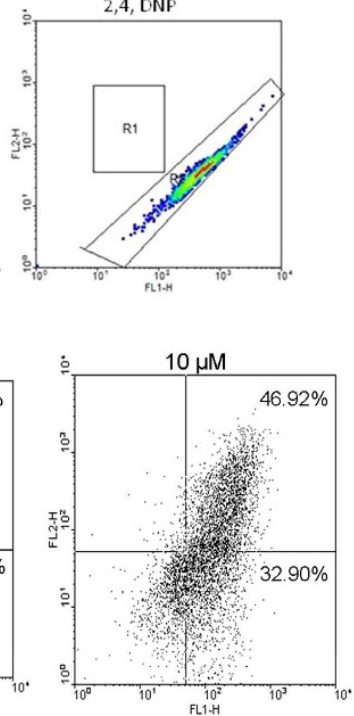

B

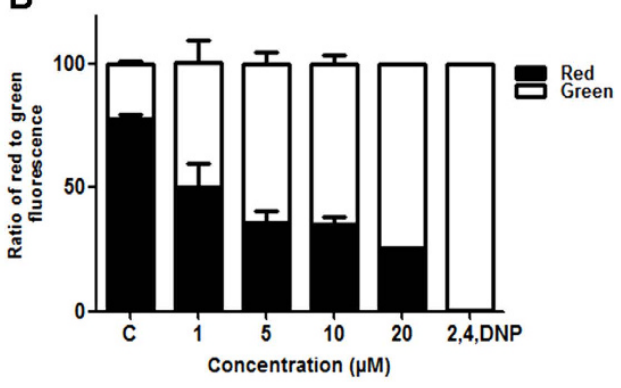

D

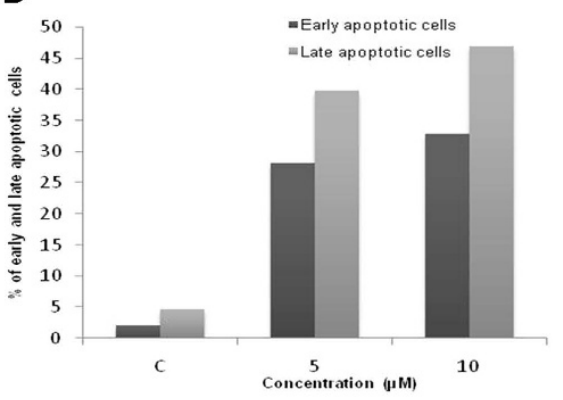

Figure 5. Effect of SS28 treatment on mitochondrial membrane potential and induction of apoptosis. CEM cells were treated with SS28 $(1,5,10,20 \mu \mathrm{M})$ for $48 \mathrm{~h}$, harvested and stained with JC- 1 dye and analyzed by flow cytometry. (A) Upper region represents the healthy cells that emit red fluorescence whereas the lower region emits the green fluorescence showing the apoptotic population. 2,4 Dinitrophenol was used as the positive control. (B) Bar graphs represent the ratio of red to green fluorescence. (C,D) Annexin V-FITC and PI staining to evaluate the effect of SS28 on CEM cells. CEM cells were treated with SS28 and \% of apoptotic cells was determined by staining with Annexin V-FITC and PI. In each panel, the lower left quadrant shows cells which are negative for both PI and Annexin V-FITC, upper left shows only PI cells which are necrotic. The lower right quadrant shows Annexin positive cells which are in the early apoptotic stage and the upper right shows the both Annexin/PI positive, which are in the late apoptosis necrosis. (C) Control cells and cells treated with SS28 are shown. (D) Histogram represents the percentage of early and late apoptotic cells.

increase in the cleaved Caspase 9 level (Fig. 6). Another marker of apoptosis, Caspase 3 also showed activation in both the cancer cells, further suggesting activation of apoptosis (Fig. 6). Besides, we also observed activation of PARP1 upon treatment with SS28 in CEM cells. Since activation of apoptosis was dependent on Caspase 3, we checked the expression levels of p53. Results showed an upregulation of p53 at $24 \mathrm{~h}$ time point followed by a decrease in the later time points (Fig. 6A,B). However, in A549 cells the expression levels of p73, which is also involved in the induction of apoptosis remained same (Fig. 6C,D).

SS28 showed inhibition of tumor progression in mice. In order to examine the in vivo effect of SS28 on tumor cell death in a mouse model, tumor was induced in BALB/c mice using EAC cells. A total of 10 mice were used per batch which included 5 tumor bearing mice (control) and 5 tumor mice treated with SS28 (experimental). The experiment was repeated three independent times. Based on the preliminary studies, we selected a dose of $15 \mathrm{mg} / \mathrm{kg}$ body weight for the investigation. After $12^{\text {th }}$ day of EAC injection, when small sized tumor was visible, the animals were treated with nine doses of SS28 (every alternate day). Results showed that there was no further tumor progression in the mice when SS28 was administered, unlike the untreated tumor control mice (Fig. 7A). Tumor progression was analysed upto 28 days in the study. Therefore, we observed that SS28 treatment resulted in inhibition of tumor cell proliferation, although we did not observe complete regression of the tumor.

Effect of SS28 on normal mice. In order to evaluate possible side effects due to SS28 treatment, a total of $10 \mathrm{BALB} / \mathrm{c}$ mice were used. Among them five animals were administered with SS28 (15 mg/kg, 9 doses) while other 5 mice were used as tumor control without any treatment. Results showed that there was no significant difference in body weight of the animals following SS28 treatment (Fig. 7B). To further check the side effects, we performed haematological, liver and kidney function assays. The mice were sacrificed on $21^{\text {st }}$ day of the treatment and used for the investigation. Results showed no significant difference in the number of RBCs and WBCs upon 

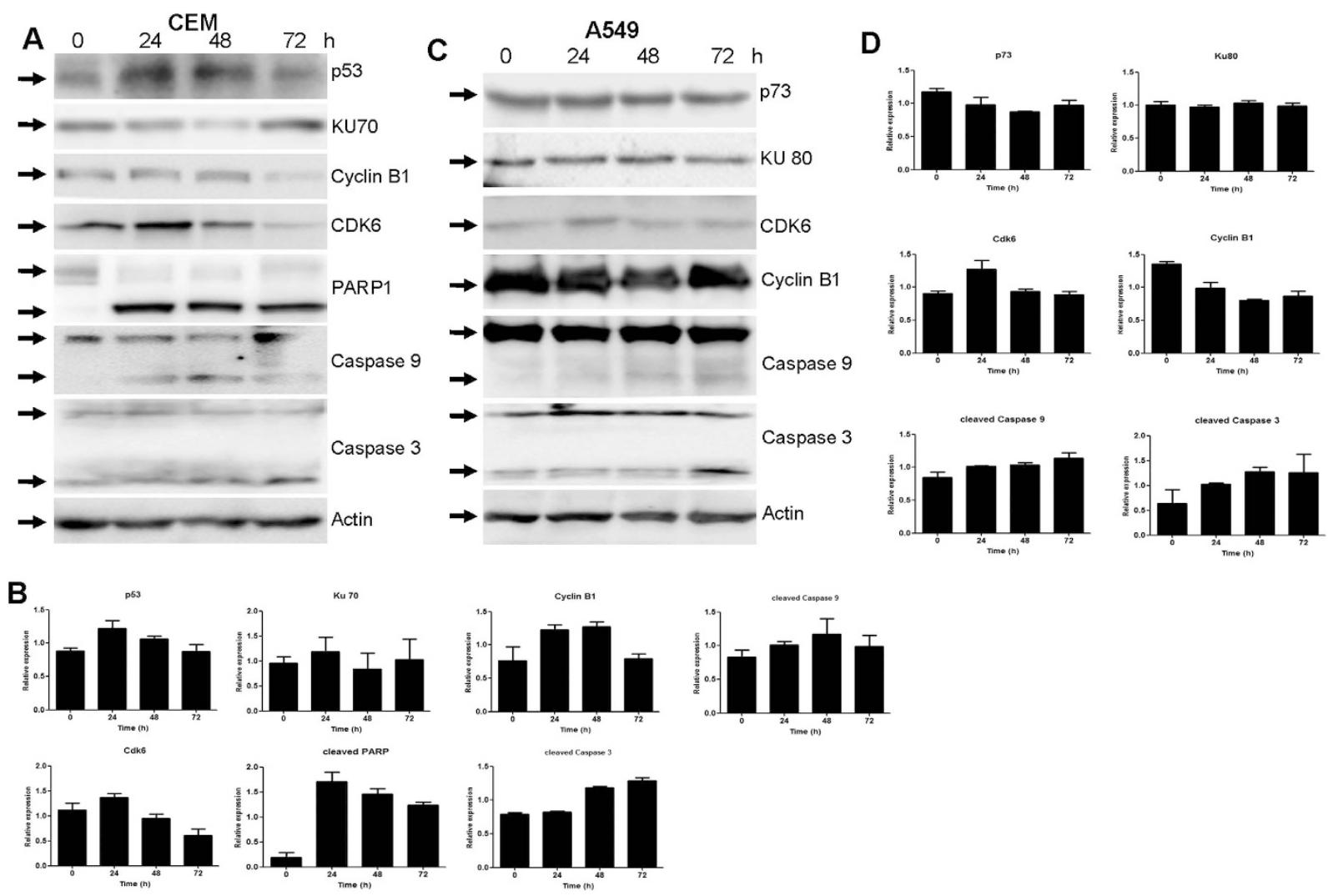

Figure 6. Expression levels of apoptotic proteins and cell cycle regulatory proteins in A549 and CEM cell lines upon treatment with SS28. A549 and CEM cells were treated with SS28 $(5 \mu \mathrm{M})$ for 24,48 and $72 \mathrm{~h}$. Whole cell lysate was prepared and proteins were resolved on a SDS-PAGE and western blotting was performed using specific primary and secondary antibodies. Blots shown are representative blots of two independent experiments with identical results. Actin was used as the loading control. (A) For CEM cells p53, Ku70, Cyclin B1, Cdk6, PARP-1, Caspase 9 and Caspase 3 proteins were evaluated. (B) Quantification of the proteins shown in panel A is represented as bar diagram with error bars. (C) For A549 cells, p73, Ku80, Cdk6, Cyclin B1, Caspase 9 and Caspase 3 proteins were evaluated. (D) Quantification of the respective proteins is shown in bar diagram with error bars.

treatment with SS28 (Fig. 7C). Further, we found that the ALP level was slightly higher in the treated animals. But there was no significant difference in the level of ALT, the marker for normal liver function, upon treatment with SS28 (Fig. 7D). Further, there was no significant difference in the levels of creatinine and urea in the serum which indicates efficient kidney function (Fig. 7E). Thus, our study indicated that SS28 treatment did not result in any major toxicity on functions of normal tissues.

Pharmacokinetics of SS28 in mice models. SS28 was administered intraperitonealy and the concentration of the compound was measured in plasma using a standard plot. Blood was drawn from the heart at $15 \mathrm{~min}, 30 \mathrm{~min}, 1$ and $2 \mathrm{~h}$ of the administration of SS28. Bioavailability data were obtained by measuring the concentration by high-performance liquid chromatography in serum samples taken at different times after SS28 administration (Fig. 7F). Results showed a significant increase in the level of SS28 in the plasma when collected $30 \mathrm{~min}$ after the injection, although the compound was detectable both at $15 \mathrm{~min}$ and $1 \mathrm{~h}$ post-treatment (Fig. 7F). We observed a significant decrease in the levels of SS28 after $1 \mathrm{~h}$ of treatment.

\section{Discussion}

Resveratrol, trans-3,5,4'-trihydroxy-trans-stilbene, is a natural polyphenol with potent chemopreventive and chemotherapeutic properties ${ }^{9,26}$. It can modulate multiple cellular processes, including apoptosis, cell cycle progression, inflammation and angiogenesis ${ }^{26}$. Moreover, previous studies have shown that hydroxy stilbenes and its derivatives can act as potential anticancer agents by targeting microtubule assembly dynamics ${ }^{27,28}$. In view of the cancer preventive and chemotherapeutic property of resveratrol, we synthesised and characterised a series of resveratrol derivatives and identified SS28 as a potent anticancer molecule ${ }^{21}$.

In the present study, we have investigated the mechanism of action of SS28 with its molecular target, Tubulin by binding studies in conjunction with the cell based assays, ex vivo and in vivo. We show that SS28 induced cytotoxicity in most of the cancer cell lines investigated, in a concentration-dependent manner. SS28 showed only limited cytotoxicty on kidney epithelial cell line and PBMCs. SS28 treatment led to G2/M phase arrest in both A549 and CEM cells followed by increased accumulation of cells in Sub G1 phase in a time dependent manner 
A

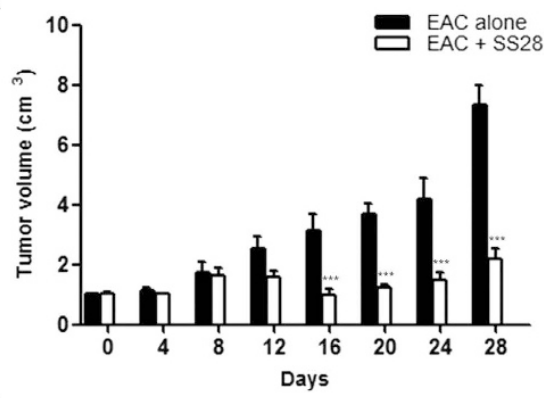

C

\begin{tabular}{|c|c|c|}
\hline & Control & $\begin{array}{c}\text { SS28 } \\
\text { Treated }\end{array}$ \\
\hline $\begin{array}{l}\mathrm{RBC}\left(10^{6}\right. \\
\left.\text { cells } / \mathrm{mm}^{3}\right)\end{array}$ & $5.23 \pm 0.99$ & $6.43 \pm 1.32$ \\
\hline $\begin{array}{l}\text { WBC }\left(10^{3}\right. \\
\left.\text { cells } / \mathrm{mm}^{3}\right)\end{array}$ & $4.27 \pm 1.01$ & $3.5 \pm 0.99$ \\
\hline
\end{tabular}

B

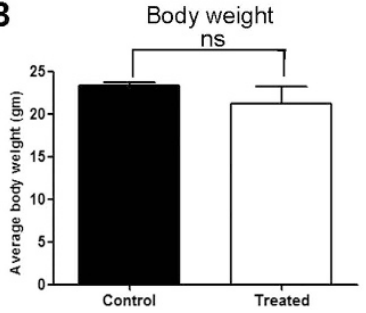

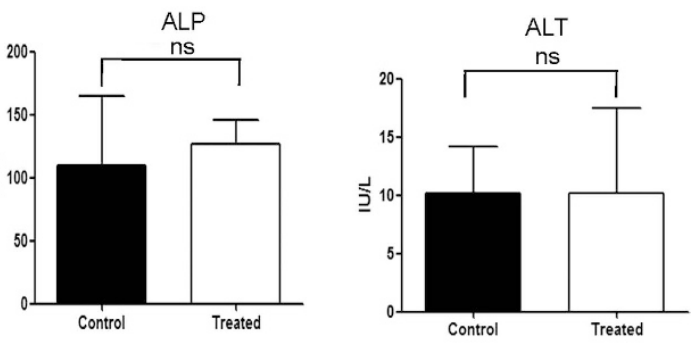

$\mathbf{F}$

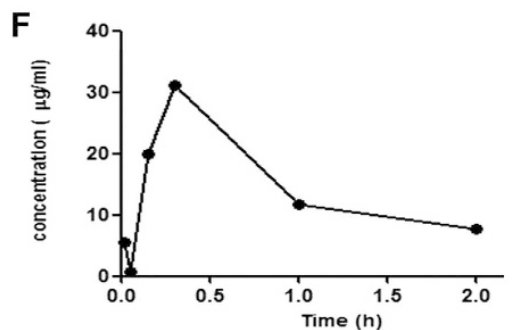

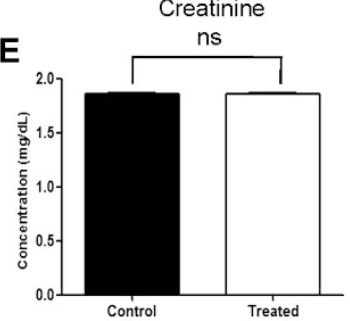

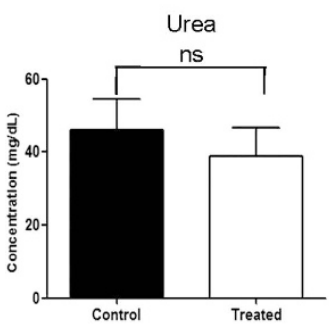

Figure 7. Impact of SS28 on tumor bearing mouse and evaluation of side effects of SS28 in normal BALB/c mice. (A) Nine doses of SS28 (15 mg/kg. b.wt.) were administered orally on every alternate day from $12^{\text {th }}$ day of EAC cell injection in mice. Data shows volume of tumor measured at different time intervals, with and without treatment of SS28. Results depicted from three independent batches of experiments containing 10 animals each. (B) Mice were orally administered with nine doses of SS28 (15 mg/kg) on every alternate day. Data represented as average body weight in both the controls and SS28 treated mice. Error bars indicate SEM. (C-E) Hematological profile and renal and liver functional assay. Blood was collected on the $21^{\text {st }}$ day of the treatment counted RBC and WBC $(C)$ and serum was tested for alkaline phosphatase (ALP), alanine aminotransferase (ALT) (D), urea and creatinine (E). Columns represent mean from five animals in each group; bars SEM. (F) Pharmacokinetics of SS28 in mice plasma. SS28 was injected intraperitonealy to mice and blood was collected and processed as described in materials and methods. Data represented in time points versus the peak area as the function of the concentration of SS28 in plasma.

suggesting activation of cell death pathways following induction of cell cycle arrest. Previous studies have shown such a cell cycle arrest by various chemotherapeutic agents. Examples include nocodazole and paclitaxel, both targeting microtubule formation resulting in the G2/M cell cycle arrest followed by apoptosis both ex vivo ${ }^{29}$ and in vivo ${ }^{30}$. Besides, the observed regulation of expression of checkpoint proteins corresponding to the cell cycle dynamics can also explain the cell cycle arrest mediated by SS28. Cyclin B1 is known to be involved in G2/M cell cycle progression, and is a regulator for G2/M transition ${ }^{31}$. SS28 treatment led to decrease in the cyclin B1 level further explaining the observed cell cycle arrest.

The assembly dynamics of spindle microtubules is crucial for chromosome segregation during mitosis. It has been shown that many antimitotic drugs inhibit mitosis at the metaphase/anaphase transition at lower concentrations primarily by suppressing microtubule dynamics ${ }^{32-36}$. We find that SS28 induced disassembly of microtubules with misconfigured chromosomes in A549 cell line. The observed effect is comparable to many other potent antimitotic drugs with respect to morphology of spindles in blocked cells ${ }^{1,37,38}$. Interestingly, we noted that SS28 treated cells exhibited more distinct structures than the colchicine treated positive controls suggesting that SS28 has strong affinity to interact with Tubulin in cells, thereby inhibiting the microtubule assembly compared to colchicine. Furthermore, the microtubule assembly assay suggests that SS28 inhibits the Tubulin polymerisation by binding to Tubulin in a concentration dependent manner.

Docking studies indicated that SS28 can bind to colchicine binding pocket in Tubulin. CD studies revealed that SS28 can bind to Tubulin leading to increased molar ellipticity indicating conformational change in protein following SS28 binding (Fig. 4A). Besides, fluorescence studies suggested a dissociation constant of $0.414 \pm 0.11 \mu \mathrm{M}$ indicating that the binding affinity of SS28 to Tubulin is comparable to that of colchicine ${ }^{39}$. Moreover, SS28 exhibited an increase in fluorescence upon binding to Tubulin, which was comparable to that known for colchicine $\mathrm{e}^{40}$. The molecular modeling data showed that methyl benzene group of SS28 can fit in the methoxytropone ring (ring C) 
of colchicine binding site on Tubulin (Fig. 3C). The results of docking studies were further supported by preliminary competition studies (data not shown). The change in the fluorescence spectra upon addition of SS28 and colchicine together indicate the binding of SS28 to the colchicine binding site on Tubulin. In support of this data, $\mathrm{AC}$, a colchicine analog, which has $\mathrm{A}$ and $\mathrm{C}$ ring, which binds to Tubulin rapidly and reversibly to its colchicine site shows increase of fluorescence ${ }^{41}$.

In an earlier study, it has been shown that methylated derivatives of flavonoids exhibit higher antiproliferative potency on cancer cells than their hydroxylated counterparts ${ }^{42}$. In the present study, the small molecule (SS28) evaluated is a methoxy derivative of resveratrol exhibiting significant anticancer properties by affecting Tubulin proliferation. Increased lipophilic properties of the methoxy derivative of resveratrol can help in increased uptake through the cell membrane, besides targeting Tubulin. Our results also support the notion that methylation of the hydroxyl groups, could be the critical modification required for interference of Tubulin polymerization.

Annexin V FITC/PI staining showed presence of both early and late apoptotic cells, which increased in a dose-dependent manner upon treatment with SS28. However, we did not find cells undergoing necrosis, which was also consistent with previous studies using resveratrol based inhibitors. Thus, cytotoxicity induced by SS28 was mainly due to apoptosis rather than necrosis. Further, the observed reduction in the mitochondrial membrane potential following treatment is consistent with induction of apoptosis by SS28. Caspase family plays a key role in apoptosis through the proteolysis of specific targets. Intracellular caspases are activated during apoptosis via two major pathways, mitochondria-mediated pathway and death receptor-mediated pathway ${ }^{43}$. Expression analysis showed activation of Caspase 3, Caspase 9 and PARP-1 suggesting activation of intrinsic pathway of apoptosis $23,43,44$.

Our data also showed that SS28 inhibited tumor cell proliferation in mouse bearing EAC tumor. EAC cells possessing malignant features of cancer are commonly used for inducing tumors in mice and for evaluating anticancer activity of small molecules in vivo ${ }^{45,46}$. Our results showed that in control animals, the tumor showed unrestricted progression, whereas in SS28 treated mice, a significant reduction in the tumor size was observed. Hematological and enzymatic assays showed that SS28 did not interfere with other cellular functions. Thus, as a proof of principle we show that the novel Tubulin inhibitor identified here inhibits tumor progression in mice without major side effects.

\section{Conclusion}

In summary, the results of the present study show that SS28, a resveratrol based Tubulin inhibitor can function as an antimitotic agent and inhibit cell proliferation in various cancer cell lines. SS28 acts by disrupting the microtubule formation by binding to Tubulin leading to cell death, which is mediated through intrinsic pathway of apoptosis in cell lines and mouse tumor tissues. Thus, our results suggest that SS28 can act as a potent microtubule targeting agent and further can be developed as an anticancer drug.

\section{Methods}

Chemicals and reagents. All the chemicals and reagents used in the present study were obtained from Sigma Chemical Co (St. Louis, MO) and SRL (India). Antibodies were purchased from Santa Cruz Biotechnology (USA) and Cell Signaling Technology (USA). Purified Tubulin was purchased from MP Biomedicals (France). Synthesis and characterization of SS28 [(E)-1,2,3-trimethoxy-5-(4-methylstyryl)benzene (6h)] has been described previously ${ }^{21}$.

Cell lines and culture conditions. Human T-cell leukemic cell line, CEM; human lung carcinoma cell line, A549; Human T-cell leukemic cell line, Molt4; human cervix adenocarcinoma cell line, HeLa; human embryonic kidney epithelial cell line, 293T, Mouse embryonic fibroblast (MEF) were purchased from National Centre for Cell Science, Pune, India. Human B cell leukemic cell lines, Reh and Nalm6 were a kind gift from Dr. M. Lieber and Diffuse large B cell lymphoma cell line, SUDHL8 was a gift from Dr. A. Epstein, USA and PBMC purchased from Saarum Biosciences, India. Cells were cultured in RPMI/MEM/Ham's F12 media 1640 (Sera Lab, USA) containing $10 \%$ FBS (GIBCO BRL, USA), $100 \mathrm{U}$ of Penicillin G/ml and $100 \mathrm{mg} / \mathrm{ml}$ of streptomycin $/ \mathrm{ml}$ at $37^{\circ} \mathrm{C}$ in a humidified atmosphere containing $5 \% \mathrm{CO}_{2}$.

Molecular modeling of SS28-Tubulin complex. 3D structure of SS28 was generated in Discovery studio package using in-built dreiding-like force field (Discovery Studio 4.0. Accelrys, USA). 3D crystal structure of $\alpha, \beta$-Tubulin bound with colchicine was retrieved from protein databank (PDB ID: 3UT5, www.rcsb.org/pdb) ${ }^{17}$. Molecular docking studies were carried out with Autodock4.2 program ${ }^{47}$. Briefly, SS28 was docked in colchicine binding site keeping the grid centres $9.45,56.62$ and 87.95 for $\mathrm{X}, \mathrm{Y}$ and $\mathrm{Z}$ respectively (npts $=50$ for X, Y and Z, spacing $=0.375$ ). Rigid docking was carried out using Lamarckian genetic algorithm (GA run was kept 20 with medium search parameter). Best pose was selected according to lower binding energy and presented in the final image using Pymol.

Circular dichroism. Purified Tubulin $(1 \mu \mathrm{M})$ was resuspended in PEM buffer (80 mM PIPES (pH 6.9), 2 mM $\mathrm{MgCl}_{2}, 0.5 \mathrm{mM}$ EGTA, $1.0 \mathrm{mM} \mathrm{GTP}$ and 5\% glycerol) and CD spectrum was recorded at a wavelength of 200 to $260 \mathrm{~nm}\left(4^{\circ} \mathrm{C}\right)$ on a JASCO J-810 spectropolarimeter. 3 cycles were acquired for each sample at a scan speed of $100 \mathrm{~nm} / \mathrm{sec}$. Increasing concentration of SS28 $(500 \mathrm{pM}, 1,10,100$ and $1000 \mathrm{nM})$ was incubated with Tubulin $(1 \mu \mathrm{M})$ in PEM buffer and the spectrum was recorded. Spectral measurements were taken for buffer alone and buffer containing DMSO were subtracted from experimental data. The molar ellipticity was calculated using Spectra Manager software and plotted as a function of wavelength.

Fluorescence polarisation. Fluorescence spectral measurements were performed using Infinite M200 PRO microplate reader (Tecan Group Ltd., Switzerland). Briefly, SS28 $(10 \mu \mathrm{M})$ was preincubated with increasing 
concentration of Tubulin $(10,25,50,100,500$ and $1000 \mathrm{nM})$ at $30^{\circ} \mathrm{C}$ for $30 \mathrm{~min}$. SS28 Tubulin complex was then scanned for the emission spectra from 345 to $545 \mathrm{~nm}$ at $315 \mathrm{~nm}$ excitation range. Resulting fluorescence intensity was plotted as the function of wavelength.

The dissociation constant $(\mathrm{Kd})$ was determined using double reciprocal plot of change in fluorescence of SS28 $(1 / \Delta(\mathrm{F} 0-\mathrm{F}))$ as a function of protein concentration by the method of Benesi and Hildebrand assuming a 1:1 binding of SS28 to Tubulin ${ }^{48}$. The spectral measurements were recorded three times and SEM was calculated.

Cell proliferation assays. The effect of SS28 on viability of CEM, Reh, Nalm6, SUDHL8, Molt4, A549, HeLa 293T, mouse embryonic fibroblast (MEF) and PBMC was determined by trypan blue dye exclusion assay as described previously ${ }^{49,50}$. Briefly, cells $\left(0.75 \times 10^{5}\right.$ cells $\left./ \mathrm{ml}\right)$ were treated with increasing concentrations of SS28 $(1,5,10$ and $20, \mu \mathrm{M})$ for 48 and $72 \mathrm{~h}$. DMSO treated cells were used as the vehicle control. Cells were harvested and subjected to trypan blue assay. Data from a minimum of three independent experiments is presented as a histogram with error bars.

MTT (3-(4,5-dimethylthiazol-2-yl)-2,5-diphenyltetrazoliumbromide) assay was performed to determine the effect of SS28 on proliferation of cells as described ${ }^{51,52}$. Briefly, CEM, Reh, Nalm6, SUDHL8, Molt4, A549, HeLa and $293 \mathrm{~T}$ cells $\left(0.5 \times 10^{5} \mathrm{cells} / \mathrm{ml}\right)$ were seeded in 24 well plate and treated with increasing concentrations of SS28 $(1,5,10,20 \mu \mathrm{M})$. MTT assay was performed after 48 and $72 \mathrm{~h}$ of incubation. The absorbance of experimental samples were divided by absorbance of untreated control, and presented as \% of inhibition and shown as a bar diagram. DMSO treated cells, served as vehicle control. Error bars were calculated based on a minimum of three independent experiments and data is presented as histogram.

Cell cycle phase distribution. Cell cycle analysis by flow cytometry was performed as previously described ${ }^{53}$. Briefly, 75,000 cells/ml (A549) were seeded in 6 well plates and grown in serum free medium for $18 \mathrm{~h}$. After synchronisation, the cells were treated with $5 \mu \mathrm{M}$ of SS28 $(6,12,18,24$ and $30 \mathrm{~h})$ and cells were processed as described before ${ }^{53,54}$. Similarly, CEM cells $(75,000$ cells $/ \mathrm{ml})$ were treated with SS28 $(2 \mu \mathrm{M})$ and harvested $(6,12$, 18,24 and $30 \mathrm{~h}$ ) and processed. Following fixation, cells were resuspended in PBS and stained with propidium iodide and evaluated in a flow cytometer (FACS Calibur, Becton Dickinson) using Cell Quest Pro software using excitation $488 \mathrm{~nm}$ laser and emission at $560 / 570 \mathrm{~nm}$. A minimum of 10,000 cells were acquired per sample and histograms were analysed using WinMDI 2.8 software.

Annexin V-FITC/PI double-staining assay. When cells undergo apoptosis, the integrity of the cell membrane is disrupted and phosphatidyl serine is exposed. Annexin V conjugated with FITC (apoptosis detection kit Santacruz, USA) has a selective affinity for phosphatidyl serine, based on which early and late apoptotic cells can be detected.

CEM cells $\left(1 \times 10^{5}\right.$ cells $\left./ \mathrm{ml}\right)$ were treated with SS28 $(5$ and $10 \mu \mathrm{M})$ for $48 \mathrm{~h}$. Cells were then harvested, washed with cold PBS and used for annexin-PI double-staining assay ${ }^{55,56}$. Samples were resuspended in $1 \mathrm{x}$ binding buffer and incubated with Annexin V-FITC $(0.4 \mathrm{~g} / \mu \mathrm{l})$ and PI $(0.05 \mathrm{mg} / \mathrm{ml})$ and analyzed by flow cytometry (FACS calibur) using CellQuest pro software at an excitation with $488 \mathrm{~nm}$ laser and emission at $530 \mathrm{~nm}^{55}$. A minimum of 10,000 cells were acquired for each sample and illustrated as dot plot using Flowing software.

Determination of mitochondrial transmembrane potential. Flow cytometric analysis of cells stained with JC- 1 was used to measure changes in mitochondrial transmembrane potential as described ${ }^{49,56}$. Briefly, cells were seeded at a density of $1 \times 10^{5}$ cells $/ \mathrm{ml}$ and treated with SS28 $(1,5,10$ and $20 \mu \mathrm{M})$. After $48 \mathrm{~h}$, cells were harvested, washed and incubated with JC-1 (5,5',6,6 tetrachloro-1, $1^{\prime}, 3,3^{\prime}$-tetraethyl benzimidazol carbocyanine iodide; Calbiochem, USA) for $15 \mathrm{~min}$. 2,4-Dinitrophenol-treated cells (2,4-DNP) served as the positive control. Cells were processed and analyzed by flow cytometry using CellQuest pro software with an excitation at $488 \mathrm{~nm}$ laser and emission at $530 \mathrm{~nm}$. JC-1 monomers emit at $530 \mathrm{~nm}$ and J-aggregates emit at $590 \mathrm{~nm}$.

Assay for intracellular ROS production. Intracellular ROS generation in cells was assessed using the oxidation-sensitive fluorescent probe 2,7 -dichlorodihydro fluorescein diacetate $\left(\mathrm{H}_{2} \mathrm{DCFDA}\right)$ as previously described $^{52,57}$. CEM cells were treated with SS28 $(5 \mu \mathrm{M})$ for 5, 10, 15, 30 and $60 \mathrm{~min}$, harvested, washed and incubated with $\mathrm{H}_{2}$ DCFDA $\left(30 \mathrm{~min}\right.$ at $37^{\circ} \mathrm{C}$ ) and then fluorescence intensity was analyzed by flow cytometry. $\mathrm{H}_{2} \mathrm{O}_{2}$ was used as the positive control.

Immunofluorescence microscopy. Immunofluorescence microscopy was performed as previously described $^{51,58}$. A549 cells were grown on coverslips coated with gelatin (0.1\%). Cells were treated with SS28 $(5 \mu \mathrm{M}, 24 \mathrm{~h})$ and were fixed with $2 \%$ p-formaldehyde $(20 \mathrm{~min}$ at RT). After $24 \mathrm{~h}$ of the treatment nonspecific antibody binding sites were blocked using FBS following which cells were incubated with antitubulin antibody (1:500) at RT. Coverslips were washed in PBS, incubated in biotinylated antimouse secondary antibody (1:500; RT for $1 \mathrm{~h})$ followed by Streptavidin-FITC (1:200). Finally, cells were mounted with DABCO and images were captured using Zeiss Fluorescence microscope and analyzed using Axio vision software. Colchicine treated cells were used as a positive control.

Microtubule assembly assay. Separation of insoluble polymerized Tubulin from soluble Tubulin dimers was performed as described ${ }^{59}$. In brief, CEM cells $\left(1 \times 10^{6}\right)$ were treated with 2,5 and $10 \mu \mathrm{M}$ of SS28 for $24 \mathrm{~h}$. Cells were harvested and washed with PBS before adding polymerization lysate buffer containing $20 \mathrm{mM}$ Tris- $\mathrm{HCl}$ (pH 6.8), $1 \mathrm{mM} \mathrm{MgCl}$, 2 mM EGTA, $20 \mathrm{~g} / \mathrm{ml}$ aprotinin, $20 \mathrm{~g} / \mathrm{ml}$ leupeptin, $1 \mathrm{mM}$ phenylmethylsulfonyl fluoride, $1 \mathrm{mM}$ orthovanadate and $0.5 \% \mathrm{NP}-40$. After centrifugation of the lysates at $15,000 \times \mathrm{g}$ for $10 \mathrm{~min}$ at $4{ }^{\circ} \mathrm{C}$, the pellets were resuspended in SDS-PAGE loading buffer and dissolved by heating at $95^{\circ} \mathrm{C}$ for $10 \mathrm{~min}$. $\alpha$-Tubulin was 
then immunoblotted for the pellet fraction containing polymerized microtubules and supernatants containing depolymerised microtubules were equalised and resolved on 8\% SDS PAGE.

Immunoblotting. Cell lysate was prepared after treating with SS28 ( $5 \mu \mathrm{M}$ for 24,48 and $72 \mathrm{~h})$ from CEM and A549 cell lines ${ }^{58,60}$. In brief, cells were harvested, washed with PBS, resuspended in lysis buffer (RIPA, $25 \mathrm{mM}$ Tris (pH 7.6), $150 \mathrm{mM} \mathrm{NaCl}, 1 \% \mathrm{NP}-40,1 \%$ sodium deoxycholate and $0.1 \%$ SDS) containing protease inhibitors. The protein lysate was cleared by centrifugation $(14,000 \mathrm{rpm}$, for $15 \mathrm{~min})$. The protein concentration in the supernatant was determined using the Bradford's assay.

For western blot analysis, $40 \mu \mathrm{g}$ proteins were resolved over $8-10 \%$ SDS-polyacrylamide gel ${ }^{60-62}$. Following gel electrophoresis, proteins were transferred to PVDF membrane (Millipore, USAQ9). The primary antibodies used were against Caspase 3, Caspase 9, p73, p53, KU70, KU80, Cyclin B1, CDK6, PARP1 and Actin (Santa Cruz Biotechnology, USA). The membrane was incubated with appropriate HRP-conjugated secondary antibody $(2 \mathrm{~h}$ at $4^{\circ} \mathrm{C}$ ). The blots were developed using chemiluminescent solution (Immobilon ${ }^{\mathrm{TM}}$ western, Millipore) and scanned by gel documentation system (LAS 3000, FUJI, Japan). Blots were stripped subsequently as per standard protocols and reprobed with anti $\beta$-Actin antibody.

In vivo experiments. Animals. All the animal experiments were performed as per the principles and guidelines of the ethical committee for animal care of Indian Institute of Science (IISc) in accordance with Indian National Law on animal care and use. The Institutional Animal Ethics Committee of Indian Institute of Science, Bangalore, India approved the experimental design of the present study (Ref. CAF/Ethics/288/2012). BALB/c mice, 8-10 week old, weighing 18-22 g were purchased from central animal facility, IISc, India and used for the study. The animals were housed in polypropylene cages and provided standard pellet diet (Agro Corporation Pvt. Ltd., Bangalore, India) and water ad libitum. The standard pellet diet is composed of $21 \%$ protein, $5 \%$ lipids, $4 \%$ crude fiber, $8 \%$ ash, $1 \%$ calcium, $0.6 \%$ phosphorus, $3.4 \%$ glucose, $2 \%$ vitamin, and $55 \%$ nitrogen-free extract (carbohydrates). The mice were maintained under controlled conditions of temperature and humidity with a $12 \mathrm{~h} \mathrm{light/dark} \mathrm{cycle.}$

Preparation of Ehrlich ascites carcinoma (EAC) cells for induction of tumor. EAC cells were collected from donor mice (Swiss albino) and resuspended in sterile saline. A fixed number of viable cells were injected into the peritoneal cavity of each recipient mouse and were allowed to multiply. The cells were withdrawn, diluted in saline and injected $\left(15 \times 10^{5}\right.$ cells/animal $)$ into the right thigh tissue of experimental animals for developing solid tumor.

Evaluation of antitumor activity of SS28 in mice models. A total number of $30 \mathrm{BALB} / \mathrm{c}$ mice were divided into three batches and were used for the present study. EAC cells $\left(15 \times 10^{5}\right.$ cells/animal $)$ were injected into right thigh for the development of solid tumor as described previously ${ }^{57,61,63}$. Among the 10 animals in each batch, 5 animals served as tumor control and the rest 5 animals received SS2 8 treatment ( $15 \mathrm{mg} / \mathrm{kg}$ b.wt.) by oral administration using gastric gavage. The dose used was selected based on preliminary studies. The first dose was given after $12^{\text {th }}$ day of tumor development ( 9 doses over a period of 3 weeks). The diameter of developing tumor was measured using vernier calipers at alternative days for entire life span of tumor animal and tumor volume was calculated using the formula $\mathrm{V}=0.5 \times \mathrm{a} \times \mathrm{b}^{2}$, where " $\mathrm{a}$ " and " $\mathrm{b}$ " indicates the major and minor diameter, respectively ${ }^{61}$.

Evaluation of toxicity of SS28 in normal mice. A total number of $10 \mathrm{BALB} / \mathrm{c}$ mice were used for the study, of which 5 animals served as normal control while, remaining 5 were treated with SS28 $(15 \mathrm{mg} / \mathrm{kg})$. Body weight of each animal was monitored throughout the experiment and average body weight was calculated on $21^{\text {st }}$ day of treatment. In order to evaluate the effect of SS28 on physiological functions, blood was collected (21 $1^{\text {st }}$ day) and analysed as described earlier ${ }^{61}$. The blood plasma was analyzed using Neubauer's chamber, and mean values of total red blood cells (RBCs) and white blood cells (WBCs) were determined. Serum was separated and kidney and liver function tests were performed for each animal, to determine alkaline phosphatase (ALP), alkaline transferase (ALT), creatinine and urea levels as described earlier ${ }^{61}$. Values are presented as mean $\pm \mathrm{SEM}$ for both the controls and SS28 administered mice.

In vivo pharmacokinetics study. HPLC analysis of serum. Control and SS28 (15 mg/kg b.wt.) treated $\mathrm{BALB} / \mathrm{c}$ mice were sacrificed and blood was collected at various time points $(15,30 \mathrm{~min}, 1$ and $2 \mathrm{~h} ; 2 \mathrm{each} / \mathrm{time}$ point) as described ${ }^{9,26}$. Plasma $(50 \mu \mathrm{l})$ was then extracted with acetonitrile, centrifuged $(3,000 \times \mathrm{g}$ for $15 \mathrm{~min})$ to remove precipitated proteins and the resulting supernatants were analyzed using HPLC (Waters, USA).

Standard solution of SS28 was prepared by dissolving increasing concentration ( 25 to $100 \mu \mathrm{M})$ of the compound in acetonitrile. Standard calibration curves were plotted using peak area against the concentration of the compound and the retention time of the compound was also determined. Plasma concentrations of the treated groups were extrapolated from standard curves constructed by linear regression in Graph-Pad Prism 4.0 software (GraphPad Software, Inc.).

Statistical Analysis. As specified, values in tables and figures are expressed as the mean \pm SEM of two to three independent experiments. Statistical comparisons were made by one-way ANOVA followed by Student's t test using Graph-Pad Prism 4.0 software (GraphPad Software, Inc.). A probability value of $<0.05$ was considered to be significant.

\section{References}

1. Jordan, M. A., Thrower, D. \& Wilson, L. Mechanism of inhibition of cell proliferation by Vinca alkaloids. Cancer Res 51, 2212-2222 (1991).

2. Lehnert, M. Clinical multidrug resistance in cancer: a multifactorial problem. Eur J Cancer 32A, 912-920 (1996).

3. Germann, U. A. P-glycoprotein-a mediator of multidrug resistance in tumour cells. Eur J Cancer 32A, 927-944 (1996). 
4. Kruczynski, A. \& Hill, B. T. Vinflunine, the latest Vinca alkaloid in clinical development. A review of its preclinical anticancer properties. Crit Rev Oncol Hematol 40, 159-173, doi: S1040-8428(01)00183-4 (2001).

5. Yvon, A. M., Wadsworth, P. \& Jordan, M. A. Taxol suppresses dynamics of individual microtubules in living human tumor cells. Mol Biol Cell 10, 947-959 (1999).

6. Rose, W. C. Taxol: a review of its preclinical in vivo antitumor activity. Anticancer Drugs 3, 311-321 (1992).

7. Sparreboom, A., van Tellingen, O., Nooijen, W. J. \& Beijnen, J. H. Preclinical pharmacokinetics of paclitaxel and docetaxel. Anticancer Drugs 9, 1-17 (1998).

8. Nonomura, S., Kanagawa, H. \& Makimoto, A. [Chemical Constituents of Polygonaceous Plants. I. Studies on the Components of Ko-J O-Kon. (Polygonum Cuspidatum Sieb. Et Zucc.)]. Yakugaku Zasshi 83, 988-990 (1963).

9. Athar, M. et al. Resveratrol: a review of preclinical studies for human cancer prevention. Toxicol Appl Pharmacol 224, 274-283, doi: S0041-008X(06)00503-510.1016/j.taap.2006.12.025 (2007).

10. Kim, A. L. et al. Resveratrol inhibits proliferation of human epidermoid carcinoma A431 cells by modulating MEK1 and AP-1 signalling pathways. Exp Dermatol 15, 538-546, doi: EXD445 10.1111/j.1600-0625.2006.00445.x (2006).

11. Baxter, R. A. Anti-aging properties of resveratrol: review and report of a potent new antioxidant skin care formulation. J Cosmet Dermatol 7, 2-7, doi: JCD354 10.1111/j.1473-2165.2008.00354.x (2008).

12. Choy, H. Taxanes in combined modality therapy for solid tumors. Crit Rev Oncol Hematol 37, 237-247, doi: S1040842800001128 (2001).

13. Signorelli, P. \& Ghidoni, R. Resveratrol as an anticancer nutrient: molecular basis, open questions and promises. J Nutr Biochem 16, 449-466, doi: S0955-2863(05)00035-5 10.1016/j.jnutbio.2005.01.017 (2005).

14. Kundu, J. K. \& Surh, Y. J. Cancer chemopreventive and therapeutic potential of resveratrol: mechanistic perspectives. Cancer Lett 269, 243-261, doi: S0304-3835(08)00252-8 10.1016/j.canlet.2008.03.057 (2008)

15. Trapp, V., Parmakhtiar, B., Papazian, V., Willmott, L. \& Fruehauf, J. P. Anti-angiogenic effects of resveratrol mediated by decreased VEGF and increased TSP1 expression in melanoma-endothelial cell co-culture. Angiogenesis 13, 305-315, doi: 10.1007/s10456-0109187-8 (2010).

16. Surh, Y. J. et al. Resveratrol, an antioxidant present in red wine, induces apoptosis in human promyelocytic leukemia (HL-60) cells. Cancer Lett 140, 1-10 (1999).

17. Hsieh, T. C., Juan, G., Darzynkiewicz, Z. \& Wu, J. M. Resveratrol increases nitric oxide synthase, induces accumulation of p53 and $\mathrm{p} 21$ (WAF1/CIP1), and suppresses cultured bovine pulmonary artery endothelial cell proliferation by perturbing progression through S and G2. Cancer Res 59, 2596-2601 (1999).

18. Bishayee, A. Cancer prevention and treatment with resveratrol: from rodent studies to clinical trials. Cancer Prev Res (Phila) 2, 409-418, doi: 1940-6207.CAPR-08-0160 10.1158/1940-6207.CAPR-08-0160 (2009).

19. Ravelli, R. B. et al. Insight into tubulin regulation from a complex with colchicine and a stathmin-like domain. Nature 428, 198-202, doi: 10.1038/nature02393 nature02393 (2004).

20. Gireesh, K. K., Rashid, A., Chakraborti, S., Panda, D. \& Manna, T. CIL-102 binds to tubulin at colchicine binding site and triggers apoptosis in MCF-7 cells by inducing monopolar and multinucleated cells. Biochem Pharmacol 84, 633-645, doi: S00062952(12)00406-6 10.1016/j.bcp.2012.06.008 (2012).

21. Rajput, S. S. et al. Synthesis of stilbene-based resveratrol analogs as cytotoxic agents. Research journal of pharmaceutical,biological and chemical sciences (2015).

22. Dorleans, A. et al. Variations in the colchicine-binding domain provide insight into the structural switch of tubulin. Proc Natl Acad Sci USA 106, 13775-13779, doi: 0904223106 10.1073/pnas.0904223106 (2009).

23. Suen, D. F., Norris, K. L. \& Youle, R. J. Mitochondrial dynamics and apoptosis. Genes Dev 22, 1577-1590, doi: 22/12/1577 10.1101/ gad.1658508 (2008).

24. Mollinedo, F. \& Gajate, C. Microtubules, microtubule-interfering agents and apoptosis. Apoptosis 8, 413-450, doi: 5142924 (2003).

25. Jeung, H. C. et al. Thymidine phosphorylase suppresses apoptosis induced by microtubule-interfering agents. Biochemical pharmacology 70, 13-21, doi: S0006-2952(05)00201-7 10.1016/j.bcp.2005.04.017 (2005).

26. Jang, M. et al. Cancer chemopreventive activity of resveratrol, a natural product derived from grapes. Science 275, 218-220 (1997).

27. Mikstacka, R., Stefanski, T. \& Rozanski, J. Tubulin-interactive stilbene derivatives as anticancer agents. Cell Mol Biol Lett 18, 368-397, doi: 10.2478/s11658-013-0094-z (2013).

28. Cushman, M. et al. Synthesis and evaluation of stilbene and dihydrostilbene derivatives as potential anticancer agents that inhibit tubulin polymerization. J Med Chem 34, 2579-2588 (1991).

29. Jordan, M. A. et al. Mitotic block induced in HeLa cells by low concentrations of paclitaxel (Taxol) results in abnormal mitotic exit and apoptotic cell death. Cancer Res 56, 816-825 (1996).

30. Milas, L. et al. Kinetics of mitotic arrest and apoptosis in murine mammary and ovarian tumors treated with taxol. Cancer Chemother Pharmacol 35, 297-303, doi: 10.1007/BF00689448 (1995).

31. Doree, M. \& Galas, S. The cyclin-dependent protein kinases and the control of cell division. FASEB J 8, 1114-1121 (1994).

32. Jordan, M. A. \& Wilson, L. Microtubules as a target for anticancer drugs. Nat Rev Cancer 4, 253-265, doi: 10.1038/nrc1317 nrc1317 (2004).

33. Desai, A. \& Mitchison, T. J. Microtubule polymerization dynamics. Annu Rev Cell Dev Biol 13, 83-117, doi: 10.1146/annurev. cellbio.13.1.83 (1997).

34. Wilson, L., Panda, D. \& Jordan, M. A. Modulation of microtubule dynamics by drugs: a paradigm for the actions of cellular regulators. Cell Struct Funct 24, 329-335 (1999).

35. Gupta, K. et al. Antimitotic antifungal compound benomyl inhibits brain microtubule polymerization and dynamics and cancer cell proliferation at mitosis, by binding to a novel site in tubulin. Biochemistry 43, 6645-6655, doi: 10.1021/bi036112v (2004).

36. Panda, D., Rathinasamy, K., Santra, M. K. \& Wilson, L. Kinetic suppression of microtubule dynamic instability by griseofulvin: implications for its possible use in the treatment of cancer. Proc Natl Acad Sci USA 102, 9878-9883, doi: 0501821102 10.1073/ pnas.0501821102 (2005).

37. Wilson, L. Properties of colchicine binding protein from chick embryo brain. Interactions with vinca alkaloids and podophyllotoxin. Biochemistry 9, 4999-5007 (1970).

38. Kuriyama, R. \& Sakai, H. Role of tubulin-SH groups in polymerization to microtubules. Functional-SH groups in tubulin for polymerization. J Biochem 76, 651-654 (1974).

39. Sherline, P., Leung, J. T. \& Kipnis, D. M. Binding of colchicine to purified microtubule protein. J Biol Chem 250, 5481-5486 (1975).

40. Bhattacharyya, B. \& Wolff, J. Promotion of fluorescence upon binding of colchicine to tubulin. Proc Natl Acad Sci USA 71, 2627-2631 (1974).

41. Bane, S., Puett, D., Macdonald, T. L. \& Williams, R. C. Jr. Binding to tubulin of the colchicine analog 2-methoxy-5-(2', 3', 4'-trimethoxyphenyl)tropone. Thermodynamic and kinetic aspects. J Biol Chem 259, 7391-7398 (1984).

42. Kandaswami, C., Perkins, E., Soloniuk, D. S., Drzewiecki, G. \& Middleton, E. Jr. Antiproliferative effects of citrus flavonoids on a human squamous cell carcinoma in vitro. Cancer Lett 56, 147-152 (1991).

43. Johnstone, R. W., Ruefli, A. A. \& Lowe, S. W. Apoptosis: a link between cancer genetics and chemotherapy. Cell 108, 153-164, doi: S0092867402006256 (2002).

44. Nabha, S. M. et al. Combretastatin-A4 prodrug induces mitotic catastrophe in chronic lymphocytic leukemia cell line independent of caspase activation and poly(ADP-ribose) polymerase cleavage. Clin Cancer Res 8, 2735-2741 (2002). 
45. Gekeler, V., Epple, J., Kleymann, G. \& Probst, H. Selective and synchronous activation of early-S-phase replicons of Ehrlich ascites cells. Mol Cell Biol 13, 5020-5033 (1993).

46. Nicholson, D. W. From bench to clinic with apoptosis-based therapeutic agents. Nature 407, 810-816, doi: 10.1038/35037747 (2000).

47. Morris, G. M. et al. AutoDock4 and AutoDockTools4: Automated docking with selective receptor flexibility. J Comput Chem 30, 2785-2791, doi: 10.1002/jcc.21256 (2009).

48. Benesi H. A. \& Hildebrand J. H. Spectrophotometric Investigation of the Interaction of Iodine with Aromatic Hydrocarbons. J. Am. Chem. Soc 71, 2703-2707 (1949).

49. Chiruvella, K. K. et al. Methyl angolensate, a natural tetranortriterpenoid induces intrinsic apoptotic pathway in leukemic cells. FEBS Lett 582, 4066-4076, doi: S0014-5793(08)00901-0 10.1016/j.febslet.2008.11.001 (2008).

50. Kavitha, C. V. et al. Novel derivatives of spirohydantoin induce growth inhibition followed by apoptosis in leukemia cells. Biochem Pharmacol 77, 348-363, doi: S0006-2952(08)00755-7 10.1016/j.bcp.2008.10.018 (2009).

51. Srivastava, M. et al. An inhibitor of nonhomologous end-joining abrogates double-strand break repair and impedes cancer progression. Cell 151, 1474-1487, doi:S0092-8674(12)01489-4 10.1016/j.cell.2012.11.054 (2012).

52. Thomas, E., Gopalakrishnan, V., Somasagara, R. R., Choudhary, B. \& Raghavan, S. C. Extract of Vernonia condensata, Inhibits Tumor Progression and Improves Survival of Tumor-allograft Bearing Mouse. Scientific reports 6, 23255, doi: 10.1038/srep23255 (2016).

53. Kavitha, C. V. et al. Propyl-2-(8-(3,4-difluorobenzyl)-2',5'-dioxo-8-azaspiro[bicyclo[3.2.1] octane-3,4'-imidazolidine]-1'-yl) acetate induces apoptosis in human leukemia cells through mitochondrial pathway following cell cycle arrest. PLoS One 8, e69103, doi: 10.1371/journal.pone.0069103 PONE-D-13-17152 (2013).

54. Somasagara, R. R. et al. Extracts of strawberry fruits induce intrinsic pathway of apoptosis in breast cancer cells and inhibits tumor progression in mice. PloS one 7, e47021, doi: 10.1371/journal.pone.0047021 (2012).

55. Srivastava, M. et al. Sapodilla plum (Achras sapota) induces apoptosis in cancer cell lines and inhibits tumor progression in mice. Sci Rep 4, 6147, doi: srep06147 10.1038/srep06147 (2014).

56. Srivastava, S. et al. Quercetin, a Natural Flavonoid Interacts with DNA, Arrests Cell Cycle and Causes Tumor Regression by Activating Mitochondrial Pathway of Apoptosis. Scientific reports 6, 24049, doi: 10.1038/srep24049 (2016).

57. Hegde, M. et al. Novel levamisole derivative induces extrinsic pathway of apoptosis in cancer cells and inhibits tumor progression in mice. PLoS One 7, e43632, doi: 10.1371/journal.pone.0043632 PONE-D-12-04857 (2012).

58. Sharma, S., Choudhary, B. \& Raghavan, S. C. Efficiency of nonhomologous DNA end joining varies among somatic tissues, despite similarity in mechanism. Cellular and molecular life sciences: CMLS 68, 661-676, doi: 10.1007/s00018-010-0472-x (2011).

59. Blagosklonny, M. V. et al. Taxol induction of p21WAF1 and p53 requires c-raf-1. Cancer Res 55, 4623-4626 (1995).

60. Sharma, S. et al. Homology and enzymatic requirements of microhomology-dependent alternative end joining. Cell death $\&$ disease 6, e1697, doi: 10.1038/cddis.2015.58 (2015).

61. Sharma, S. et al. A novel DNA intercalator, 8-methoxy pyrimido[4',5':4,5]thieno (2,3-b)quinoline-4(3H)-one induces apoptosis in cancer cells, inhibits the tumor progression and enhances lifespan in mice with tumor. Mol Carcinog 52, 413-425, doi: 10.1002/ mc.21867 (2013).

62. Tadi, S. K. et al. Microhomology-mediated end joining is the principal mediator of double-strand break repair during mitochondrial DNA lesions. Molecular biology of the cell 27, 223-235, doi: 10.1091/mbc.E15-05-0260 (2016).

63. Noaman, E., Badr El-Din, N. K., Bibars, M. A., Abou Mossallam, A. A. \& Ghoneum, M. Antioxidant potential by arabinoxylan rice bran, MGN-3/biobran, represents a mechanism for its oncostatic effect against murine solid Ehrlich carcinoma. Cancer Lett 268, 348-359, doi: S0304-3835(08)00321-2 10.1016/j.canlet.2008.04.012 (2008).

\section{Acknowledgements}

We thank Ms. Supriya Vartak, Ms. Monica Pandey, and Mr. Robin Sebastian for critical reading of the manuscript, discussions and help. This work was supported by grant from IISc-DBT partnership programme [DBT/BF/PR/ INS/2011-12/IISc] for S.C.R. E.T. is supported by DST postdoctoral fellowship programme, India, V.G. by SRF, CSIR, India.

\section{Author Contributions}

B.C., S.C.R. and E.T. conceived and coordinated the study, and wrote the paper. S.C.R., B.C., S.S.K. and E.T. designed the experiments. E.T., V.G., M.H., S.K. and B.C. performed the experiments. B.C., S.C.R. and E.T. analyzed the data. All authors reviewed the results and approved the final version of the manuscript.

\section{Additional Information \\ Supplementary information accompanies this paper at http://www.nature.com/srep}

Competing financial interests: The authors declare no competing financial interests.

How to cite this article: Thomas, E. et al. A Novel Resveratrol Based Tubulin Inhibitor Induces Mitotic Arrest and Activates Apoptosis in Cancer Cells. Sci. Rep. 6, 34653; doi: 10.1038/srep34653 (2016).

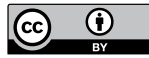

This work is licensed under a Creative Commons Attribution 4.0 International License. The images or other third party material in this article are included in the article's Creative Commons license, unless indicated otherwise in the credit line; if the material is not included under the Creative Commons license, users will need to obtain permission from the license holder to reproduce the material. To view a copy of this license, visit http://creativecommons.org/licenses/by/4.0/

(c) The Author(s) 2016 